\title{
Recurrent Hemoptysis in a Young Man
}

\author{
Madiha Mahfoudhi, Imen Gorsane, Mounira El Euch, Sami Turki, Taieb Ben Abdallah \\ Internal Medicine Department, Charles Nicolle Hospital, Tunis, Tunisia \\ Email: madiha mahfoudhi@yahoo.fr
}

Received 12 December 2014; accepted 17 August 2015; published 20 August 2015

Copyright $@ 2015$ by authors and Scientific Research Publishing Inc.

This work is licensed under the Creative Commons Attribution International License (CC BY).

http://creativecommons.org/licenses/by/4.0/

c) (i) Open Access

\begin{abstract}
Hughes-Stovin syndrome is a scarce entity associating pulmonary artery aneurysms and deep venous thrombosis. It was considered to be a form of Behcet's syndrome at its initial feature. We present a case of a 27-year-old man having a Hughes-Stovin syndrome. The patient had a history of left ilio-femoral thrombosis and suffered from recurrent oral ulcers. He presented with recurrent hemoptysis. A giant pulmonary aneurysm was confirmed by chest CT scan. A right femoral thrombosis was shown on the inferior legs doppler ultrasonography. The patient was treated by steroids and cyclophosphamide and proposed to an embolization to prevent recurrence of symptoms.
\end{abstract}

\section{Keywords}

\section{Hemoptysis, Pulmonary Aneurysm, Hughes-Stovin Syndrome}

\section{Introduction}

Hughes-Stovin syndrome is a rare pathology associating pulmonary artery aneurysms and deep vein thrombosis and affecting commonly the young patient with a masculine predominance [1] [2].

The exact etiopathogenesis in Hughes-Stovin syndrome is unrecognized [2] [3].

The etiological research is negative [1]. Several symptoms are typical to be found in this syndrome as fever, cough, hemoptysis, dyspnea, and chest pain. It's regarded according to some authors as a variant of Behçet's disease. The radiographic, angiographic and histological results concerning venous thrombosis and arterial pulmonary aneurysm were similar in the both pathologies.

Nevertheless, main symptoms of Behçet's disease as oral or genital ulcerations, skin hypersensitivity and uveitis aren't described in the published features of Hughes-Stovin syndrome.

The initial feature consists of the signs of the thrombosis; then, single or multiple pulmonary aneurysms are formed with a high risk of hemoptysis, haemorrhage and death. Deep vein thrombosis can involve the vena cava and the right atrium with a presence of lymphocytes and monocytes in histological examination of arterial or venous walls [3]-[5]. 
This syndrome, if not treated shortly, may lead to death because of serious hemoptysis which can be due to aneurismal rupture and active vasculitis.

The management of this syndrome can either be medical or surgical [1].

The aim of this study is to highlight the pejorative prognosis of recurrent hemoptysis in Hughes-Stovin syndrome and focus on its similarities with Behcet's disease which is considered as its principal differential diagnosis.

\section{Case Report}

A 27-year-old-man was hospitalized for recurrent hemoptysis occurring for last two years. The patient had presented three years ago a left femoral vein thrombosis. He received an anticoagulant treatment during 6 months. The patient had also developed recurrent oral aphthous ulcers in the past year. The physical examination showed oral ulcers, a tachycardia of 100 pulses/ min and a blood pressure of 120/60 $\mathrm{mm}$ of $\mathrm{Hg}$. There were no clinical signs of deep or superficial thrombosis. The ophthalmological examination didn't diagnose either uveitis or vasculitis.

Laboratory studies found no sign of inflammatory syndrome. He had a microcytic hypochromic anemia (hemoglobin: $11 \mathrm{~g} / \mathrm{dl}$ ) with a low level of blood iron and ferritin, a white blood cells count of $8600 / \mathrm{mm}^{3}$ and a normal platelets count of $278,000 / \mathrm{mm}^{3}$. The coagulation tests, the renal and the hepatic functions were normal. He had no proteinuria. Besides, the bacteriological examination in search for mycobacterium tuberculosis and the quantiferon gold were negative.

The immunological (ANA, RF and antiphospholipid antibodies, anti-GBM) investigations were also negative.

He had no HLA B 51. The chest radiograph revealed a left surrounded para-hilar opacity associated to linear calcifications (Figure 1).

The inferior legs doppler ultrasonography confirmed a thrombosis of the right femoral vein. The CT of the chest confirmed the presence of a giant aneurysm in the left lower lobe pulmonary artery of $90 \mathrm{~mm} / 72 \mathrm{~mm}$, partially thrombosed, occupying the quasi-totality of the left pulmonary field.

All abnormalities of hemostasis, a tumoral origin, a vasculitis and an infectious etiology were eliminated in our patient.

He had only one major criteria of Behçet's disease which is oral ulcerations, but he had no skin lesions, nor genital ulcerations. Uveitis was also missing. The diagnosis of Behcet's disease was rejected since our patient hadn't sufficient criteria for this pathology. Therefore, Hughes-Stovin syndrome, characterized by the simultaneous presence of deep venous thrombosis and pulmonary artery aneurysm, was our diagnosis.

The patient was put on systemic steroids at the dose of $1 \mathrm{mg} / \mathrm{kg} / \mathrm{day}$, and intravenous

cyclophosphamide; the steroids were subsequently tapered and withdrawn after 6 months until reaching a minimal dose of $10 \mathrm{mg} /$ day. Aspirin and anticoagulation were avoided in view of hemoptysis.

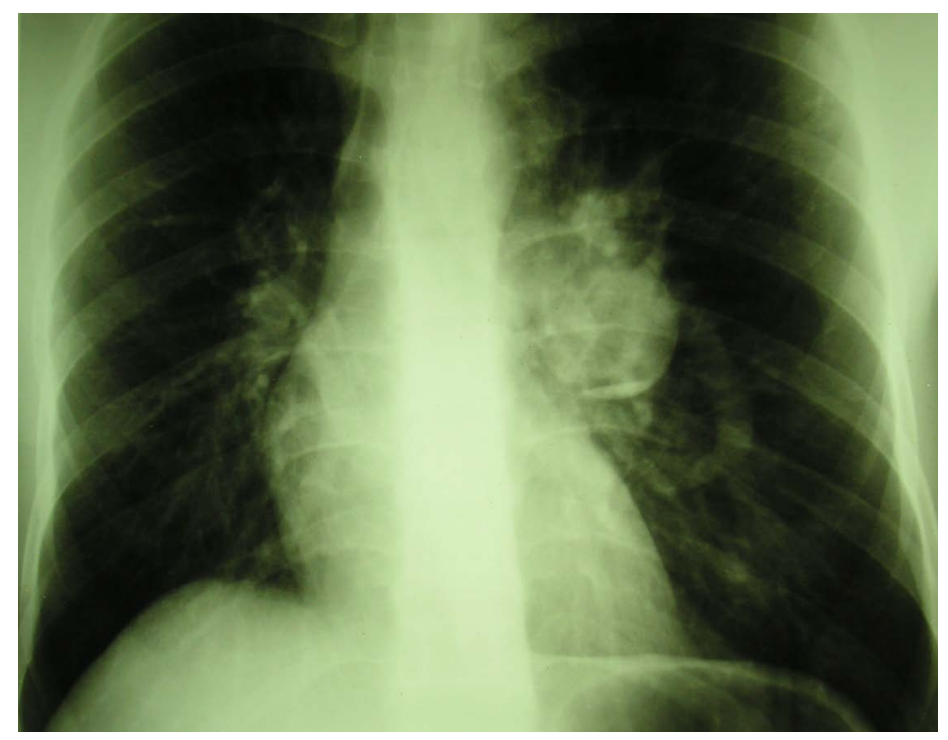

Figure 1. Chest Radiography: A round opacity in the left medial pulmonary field. 
One year of follow up has demonstrated the resolution of oral ulcers. There has been no recurrence of deep venous thrombosis, or hemoptysis. There was no evidence of enlargement of the pulmonary artery aneurysms on chest CT scan control. He was programmed for an embolization because of the giant aspect of the aneurysm.

\section{Discussion}

The Hughes-Stovin syndrome is rare in woman; the female involvement was reported in few publications [4].

It was evoked in our patient after eliminating all differential diagnosis as Behcet's disease, innate or acquired thrombophilia.

The clinical feature is commonly revealed by a recurrent hemoptysis [3]-[6].

The $\mathrm{X}$ ray and $\mathrm{CT}$ scan of the chest confim the pulmonary aneurysm. It can be unilateral like our patient or bilateral as described in some publications [6].

For that reason, bronchial arteriography must be realized promptly in case of Hughes-Stovin syndrome suspicion. Conventional angiography can be done to determine the number and the location of pulmonary aneurysms [7]. However, Contrast-Enhanced MRA and Contrast-Enhanced MDCTA (multi-detector row helical CT angiography) may demonstrate morphological bronchial arteries anomalies in early stage of the illness before the occurrence of aneurysm complication [8] [9].

The deep vein thrombosis is often clinically symptomatic but it can be latent. An antecedent of deep venous thrombosis should be researched by the interrogatory [6]. The doppler ultrasonography and/or the angioscanner confirm the venous thrombosis and its location.

All the signs, other of the pulmonary aneurysm and the deep venous thrombosis, are not essential for the positive diagnosis of Hughes-Stovin syndrome. The clinician should verify if these signs correspond to Behcet's disease criteria eliminating then the diagnosis of Hughes-Stovin syndrome.

The main medical treatment is based on systemic corticosteroids [4] [5], alone or associated to immunosuppressant [4] [9] [10] since histological examination can show a vasculitis [2].

Choh, NA et al. prescribed systemic steroids, and azathioprine (in view of pulmonary vasculitis and aneurysm formation) with a good clinical and radiological response [6].

In our case the association of corticosteroids to cyclophosphamide allowed stabilization of the clinical and radiological feature. Neither recurrence of hemoptysis nor enlargement of the aneurysm was noted during our follow up [6].

To prevent other thrombotic complications, anticoagulants and platelet inhibitors can be prescribed, but they are avoided by the most of authors because of the high hemorrhagic risk in these cases [6]. In a 18-year-old man having a Hughes Stovin syndrome, a hemoptysis had occurred after 10 days of heparin therapy and was jugulated by intranenous methylprednisolone after about 25 days [5].

Invasive surgical resection such as pneumectomy was applied to avoid lethal course of recurrent hemoptysis. A right upper lobectomy was performed in a case of Hughes Stovin syndrome because the right upper-lobe aneurysm reached too far into the periphery to allow reconstruction [2].

However, selective treatment of the arterial complications of Hughes-Stovin syndrome such as embolization is more successful and has fewer side effects [3] [10] [11].

Massive pulmonary hemorrhage caused by rupture of an aneurysm is a serious terminal event [2]. Early diagnosis and adequate treatment improve the prognosis of patients with Hughes-Stovin syndrome.

\section{Conclusions}

A Hughes-Stovin syndrome is to be researched in a young men presenting with venous thrombosis associated with hemoptysis in the absence of hemostasis abnormalities.

Chest CT scan and bronchial arteriography should be performed in each patient suspected of having HughesStovin syndrome.

The similarity among the clinical, histological and radiological features of Hughes-Stovin syndrome and Behcet's disease can induce diagnostic difficulties.

\section{Disclosure Statement}

The Authors have nothing to disclose. 


\section{References}

[1] Hughes, J.P. and Stovin, P.G.I. (1959) Segmental Pulmonary Artery Aneurysms with Peripheral Venous Thrombosis. British Journal of Diseases of the Chest, 53, 19-27. http://dx.doi.org/10.1016/S0007-0971(59)80106-6

[2] Kindermann, M., Wilkens, H., Hartmann, W., Schäfers, H.J. and Böhm, M. (2003) Hughes-Stovin Syndrome. Circulation, 108, e156. http://dx.doi.org/10.1161/01.cir.0000106680.35316.16

[3] Khalid, U. and Saleem, T. (2011) Hughes-Stovin Syndrome. Orphanet Journal of Rare Diseases, $6,15$. http://dx.doi.org/10.1186/1750-1172-6-15

[4] Al-Jahdali, H. (2010) Massive Hemoptysis and Deep Venous Thrombosis Presenting in a Woman with Hughes-Stovin Syndrome: A Case Report. Journal of Medical Case Reports, 4, 109. http://dx.doi.org/10.1186/1752-1947-4-109

[5] Chalazonitis, A.N., Lachanis, S.B., Mitseas, P., Argyriou, P., Tzovara, J., Porfyrides, P., et al. (2009) Hughes-Stovin Syndrome: A Case Report and Review of the Literature. Cases Journal, 2, 98. http://dx.doi.org/10.1186/1757-1626-2-98

[6] Choh, N.A., Jehangir, M., Mir, K.M., Kuchay, S. and Wani, N.A. (2011) Hughes-Stovin Syndrome: A Rare Cause of Hemoptysis. Lung India, 28, 285-286. http://dx.doi.org/10.4103/0970-2113.85691

[7] Ketchum, E., Zamanian, R. and Fleischmann, D. (2005) CT Angiography of Pulmonary Artery Aneurysms in HughesStovin Syndrome. American Journal of Roentgenology, 185, 330-332. http://dx.doi.org/10.2214/ajr.185.2.01850330

[8] Remy-Jardin, M, Bouaziz, N., Dumont, P., Brillet, P.Y., Bruzzi, J. and Remy J. (2004) Bronchial and Nonbronchial Systemic Arteries at Multi-Detector Row CT Angiography: Comparison with Conventional Angiography. Radiology, 233, 741-749. http://dx.doi.org/10.1148/radiol.2333040031

[9] Lee, J., Noh, J.W., Hwang, J.W., Kim, H., Ahn, J.K., Koh, E.M., et al. (2005) Successful Cyclophosphamide Therapy with Complete Resolution of Pulmonary Artery Aneurysm in Hughes-Stovin Syndrome Patient. Clinical Rheumatology, 570, 570.

[10] Tzilalis, V.D., Vourliotakis, G., Tsironis, I.A., Tsiligiris, V.D. and Brountzos, E.N. (2011) Use of an Amplatzer Vascular Plug in Embolization of a Pulmonary Artery Aneurysm in a Case of Hughes-Stovin Syndrome: A Case Report. Journal of Medical Case Reports, 5, 425. http://dx.doi.org/10.1186/1752-1947-5-425

[11] Mangini, M., Laganà, D., Fontana, F., Ianniello, A., Nicotera, P., Petullà, M., et al. (2008) Use of Amplatzer Vascular Plug (AVP) in Emergency Embolisation: Preliminary Experience and Review of Literature. Emergency Radiology, 15, 153-160. http://dx.doi.org/10.1007/s10140-007-0696-8 